\title{
MODELO GERAL DAS ATIVIDADES DA EMPRESA
}

\section{GESTÃO \\ $\&$ \\ PRODUÇÃO}

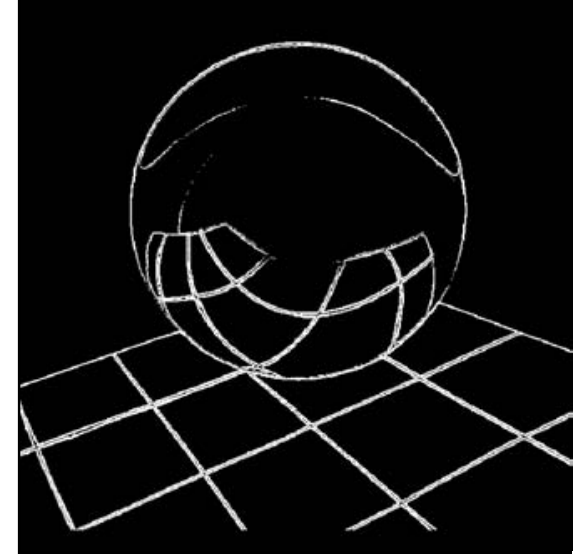

v.8, n.3, p.219-236, dez. 2001
José Celso Contador

Professor livre-docente da UNESP

Professor titular da UNIP Professor da UNINOVE

Professor da Tancredo Neves E-mail: celconta@iconet.com.br

\section{Resumo}

O modelo evidencia que as atividades de qualquer tipo de empresa, inclusive a de serviços, podem ser organizadas em quatro grupos (produção, atendimento, apoio e planejamento) e que essa organização é aplicável à empresa como um todo, a qualquer órgão (departamento, seção) e a qualquer célula de trabalho, inclusive a constituída por apenas um funcionário. $O$ modelo, por mergulhar, como nenhum outro, nas profundezas da empresa, complementa outros modelos (Tavistock, Katz \& Kahn, Kast \& Rosenzweig). A comparação com o modelo da Cadeia de Valores de Porter e as vantagens apontadas no texto permitem concluir que o modelo é bastante adequado para a proposição de mudanças na empresa que melhorem sua posição competitiva.

Palavras-chave: modelo organizacional, atividades empresariais, estratégia, empresa industrial e de serviços.

\section{Introdução}

$\bar{Z}^{\text {ste artigo objetiva lançar à discussão }}$ - acadêmica um novo, e pelo que se sabe inédito, modelo para representar a essência das atividades de qualquer tipo de empresa.
O modelo das atividades da empresa é um modelo geral, pois se aplica a qualquer tipo de empresa, à empresa como um todo, a qualquer unidade organizacional da empresa e à menor célula organizacional (um funcionário). Sua característica fundamental é mostrar que as 
atividades de qualquer órgão, em qualquer nível hierárquico, podem sempre ser organizadas segundo uma mesma estrutura, que inclui tipos de atividades e suas interações. Ou seja, abrindo um órgão, vai se encontrar dentro dele vários subórgãos com os mesmos tipos de atividades e com as mesmas interações. Entender a empresa pela óptica desse modelo traz muitas vantagens, expostas ao longo do texto.

Uma questão inquieta o autor há trinta anos: a empresa de serviços é diferente da industrial? Nessa inquietação está a gênese do modelo.

A resposta a essa questão é não. Não, a empresa de serviços não é diferente da empresa industrial. Mas convém dá-la de outra forma: a empresa de serviços difere da empresa industrial tanto quanto a empresa de uma indústria difere da de outra, tanto quanto uma fábrica de confecções difere de uma fábrica de autopeças. Obviamente, os processos produtivos são diferentes: o processo de uma siderúrgica é diferente do de uma metalúrgica, o processo de uma lavanderia é diferente do de um restaurante ou do de um banco.

É importante mencionar que, durante seu desenvolvimento, o modelo assumiu importância muito maior do que a de responder à questão sobre as semelhanças ou dessemelhanças entre a empresa de serviços e a industrial. A óptica adotada acabou por resultar num modelo que, na opinião do autor, é o mais adequado para a análise e decisão sobre o melhor caminho que a empresa deve adotar com a finalidade de aumentar o seu grau de competitividade, como será mostrado.

O modelo tenderá a ser, portanto, valioso instrumento da Teoria da Competitividade. E também de outras teorias, pois auxilia o entendimento sobre o funcionamento da empresa e facilita a introdução de mudanças.

\section{O Motivo da Busca por um Modelo Geral}

Nos textos de economia, tem sido tradicional classificar as empresas em:

- empresa do setor primário $\rightarrow$ empresa extrativa (agropecuária, mineração etc.);
- empresa do setor secundário $\rightarrow$ empresa de transformação (indústria); e

- empresa do setor terciário $\rightarrow$ empresa de serviços (comércio e serviços).

Essa classificação pode induzir alguns a pensar que uma empresa de um desses setores é diferente da de outro setor. Engano. Para os fins da ciência administrativa, as empresas dos três setores são iguais na sua essência. Ressalve-se entretanto que, especificamente, não existem duas empresas iguais na sua forma final, mesmo dentro de um estreito setor. Entretanto, um modelo mestre, comum a qualquer empresa, pode evidenciar essa essência.

Qual o interesse em descobrir a essência? Em descobrir se a empresa de serviços é igual ou diferente da empresa industrial? O interesse mais importante é começar a desvendar a essência das técnicas administrativas, desnudando-as da roupagem que se revestem para atender aos detalhes deste ou daquele produto ou serviço. Mais especificamente, o interesse está na possibilidade da utilização de idênticas técnicas administrativas a qualquer tipo de empresa, principalmente com a finalidade de alcançar vantagens competitivas. Tentar desvendar essa essência foi o que motivou a busca de um modelo geral das atividades da empresa.

Compare-se, a título ilustrativo, a diferença entre a evolução da produtividade e da qualidade ocorrida na indústria e na empresa de serviços.

A produtividade da maioria das empresas de serviços é muito baixa, não obstante alguns ramos terem conseguido, nos últimos anos, aumentá-la de forma expressiva, como o bancário, o de supermercados e o de fast food. É notório que os ganhos de produtividade obtidos pela indústria foram gigantescos desde a Revolução Industrial, tempo em que se utilizavam teares manuais. E não apenas devido aos avanços tecnológicos, mas também devido à evolução da ciência administrativa, desde a época de Taylor no final do século XIX.

A qualidade da maioria dos serviços é censurável. Para os produtos industrializados, a melhoria foi significativa. Basta mencionar, a título 
ilustrativo, que o índice de defeitos de fabricação, em meados da década de 1980, era medido em valores percentuais e, hoje, em número de defeitos por milhão de peças produzidas; ou seja, uma melhoria superior a mil vezes.

Ora, se as técnicas desenvolvidas pela e para a indústria fossem utilizadas no setor de serviços, os ganhos de produtividade e a melhoria na qualidade dos serviços poderiam ser também altamente significativos. Isto feito, acarretaria uma conseqüência muito importante: as vantagens competitivas decorrentes não só da maior produtividade e da melhor qualidade, mas também da maior flexibilidade, da maior confiabilidade e da maior rapidez na produção dos serviços poderiam ser alcançadas num tempo bem menor do que o gasto pela indústria, pois as empresas de serviços não precisariam desenvolver técnicas.

A possibilidade de usar técnicas similares às da empresa de qualquer setor econômico é também muito importante para a indústria, porque permitirá à empresa industrial utilizar, na área de atendimento, todas as técnicas administrativas desenvolvidas pelas e para as empresas de serviços, acelerando os ganhos de competitividade decorrentes das atividades de atendimento.

Enfim, o que motivou a busca por um modelo geral de atividades foi a possibilidade de identificar as similaridades de problemas administrativos aparentemente diferentes e de transferir soluções percebidas na empresa de serviços para a industrial e vice-versa. Como o que mais diferencia, pelo senso comum, a empresa de serviços da industrial são as áreas de produção e de atendimento, a motivação foi a possibilidade de transplantar os avanços administrativos de uma empresa para outra, ou seja, aplicar, à produção de serviços, as técnicas desenvolvidas para a produção fabril e aplicar, às atividades de atendimento da indústria, as técnicas administrativas desenvolvidas para o setor de serviços.

\section{O Modelo Geral das Atividades da Empresa} uma quantidade infindável de técnicas.
Infindável porque novidades surgem constantemente, geralmente desenvolvidas para ou por uma empresa, ora de um setor, ora de outro.

Analisando-as, observa-se que essas técnicas são típicas ou estanques de cada área da empresa. Assim, administrativamente, as atividades de qualquer empresa podem ser agrupadas em função das técnicas utilizadas para sua operação.

Por este critério, é adequado o agrupamento das atividades da empresa de qualquer setor econômico em quatro conjuntos, de forma que, em cada conjunto, seja possível a utilização de técnicas similares:

- atividades planejadoras, ou simplesmente planejamento;

- atividades apoiadoras, ou simplesmente apoio;

- atividades produtoras de bens e serviços, ou simplesmente produção; e

- atividades atendedoras, ou simplesmente atendimento.

Agregar as atividades da empresa em quatro áreas:

- planejamento

- apoio

- produção

- atendimento

possibilita usar as técnicas administrativas típicas ou estanques de cada área para empresas de qualquer setor econômico.

Produção industrial ou produção agrícola são expressões corriqueiras. Porém, mencionar que uma empresa de serviços tem produção pode soar estranho. Mas, todo e qualquer serviço precisa ser produzido: o restaurante precisa produzir refeições, o hotel precisa produzir roupa lavada e outras condições para hospedar, o dentista precisa produzir a restauração do dente cariado, a televisão precisa produzir a novela. Essas atividades, no setor de serviços, são conhecidas por atividades de retaguarda ou de back room.

As atividades atendedoras são aquelas realizadas na presença física do cliente ou à distância, como as do maître, as do concièrge, as 
do telemarketing e as do vendedor de uma empresa industrial. Essas atividades, no setor de serviços, são conhecidas por atividades de frente ou de front office.

As atividades apoiadoras são aquelas ditas administrativas, como as das áreas financeira, de compras, de gestão de materiais, de recursos humanos.

As atividades planejadoras são aquelas realizadas anteriormente à produção ou ao atendimento, como as relativas ao estabelecimento de estratégias, ao marketing e ao projeto do produto, do serviço e dos sistemas.

Um primeiro e simples exemplo é conveniente para ilustrar os conceitos. O contato e o diálogo com o cliente são as atividades atendedoras de uma vendedora de flores, sendo importante a cortesia, a atenção, a simpatia. O arranjo do ramalhete é uma atividade produtora, na qual o importante é saber fazer bem o serviço. A consulta ao cadastro de clientes é uma atividade apoiadora ao atendimento. A preparação do papel e da fita para o laço, assim como de outros materiais necessários à apresentação estética do ramalhete, é uma atividade apoiadora à produção. Dentre as atividades planejadoras, está a decisão sobre a quantidade de flores a encomendar ao fornecedor.

A Figura 1 mostra as atividades produtoras e atendedoras típicas de alguns tipos de empresa com o intuito de começar a esclarecer as idéias contidas no modelo.

A Figura 2 apresenta o modelo geral das atividades da empresa, evidenciando que uma mesma estrutura, que inclui os tipos de atividades e suas interações, vale para a empresa, para seus departamentos e para um funcionário. A denominação departamento é meramente ilustrativa, pois a estrutura vale para qualquer órgão da empresa, conceituado na seção 4.

Como será mostrado ao longo do artigo, o modelo é aplicável à empresa industrial e à de serviços. Especificamente em relação à de serviços, o modelo atende às três classes de serviços propostas por SILVESTRO (1999, p. 401) no Modelo dos processos de serviços, quais sejam, serviços profissionais, lojas ou oficinas de serviços e serviços de massa.

\section{Definição das Atividades do Modelo}

$\mathbf{E}^{\text {ntende-se por: }}$

- órgão da empresa: qualquer uma de suas unidades organizacionais em qualquer nível hierárquico (seção, departamento etc.);

- célula da empresa: qualquer posto de trabalho, ocupado por uma ou por várias pessoas, contendo ou não máquinas ou equipamentos;

- área: o agrupamento de atividades da empresa, mostrado na Figura 2, correspondendo a quatro áreas para toda empresa: produtora, atendedora, apoiadora e planejadora; e

- subárea: o agrupamento de atividades em cada órgão da empresa, como ilustrado na Figura 2, correspondendo a quatro subáreas para cada órgão: produtora, atendedora, apoiadora e planejadora.

É conveniente esclarecer que uma área ou uma subárea não corresponde necessariamente a uma unidade organizacional, aqui denominada órgão.

Na área planejadora, constituída por diversos órgãos, estão compreendidas as atividades realizadas anteriormente ao apoio, à produção e ao atendimento, principalmente:

- definição das estratégias gerais da empresa, como as estratégias de produção, de atendimento, de comunicação com o mercado, de comercialização, de marketing, de recursos humanos, de finanças;

- pesquisa e desenvolvimento de tecnologia de produto, de serviço e de todos os processos existentes (de produção, de atendimento, de apoio e de planejamento);

- estabelecimento da estratégia e da política geral de gestão da informação e de sistemas, definindo quais sistemas desenvolver, quais comprar e seu nível de integração; e

- gestão do conhecimento, em termos de capacitação, disseminação e uso do conhecimento empresarial. 
EXEMPLOS DE AGRUPAMENTO DE ATIVIDADES

\begin{tabular}{|c|c|c|}
\hline Tipo de empresa & Produção & Atendimento \\
\hline Hotel & $\begin{array}{l}\text { lavanderia } \\
\text { cozinha } \\
\text { governança } \\
\text { manutenção }\end{array}$ & $\begin{array}{c}\text { recepção } \\
\text { conciergérie } \\
\text { salão de refeições } \\
\text { caixa }\end{array}$ \\
\hline Restaurante & $\begin{array}{l}\text { cozinha } \\
\text { bar } \\
\text { limpeza }\end{array}$ & $\begin{array}{l}\text { atendimento pelo garçom } \\
\text { atendimento pelo maître } \\
\text { atendimento pelo barman }\end{array}$ \\
\hline Lavagem de automóvel & $\begin{array}{c}\text { lavagem } \\
\text { polimento }\end{array}$ & recepção \\
\hline Consultório dentário & $\begin{array}{c}\text { obturação } \\
\text { extração } \\
\text { preparação da prótese }\end{array}$ & $\begin{array}{l}\text { atendimento durante a obturação } \\
\text { atendimento durante a extração } \\
\text { diagnóstico } \\
\text { marcação de consulta }\end{array}$ \\
\hline Transporte urbano & $\begin{array}{c}\text { viagem } \\
\text { limpeza dos veículos } \\
\text { manutenção }\end{array}$ & $\begin{array}{c}\text { atendimento durante a viagem } \\
\text { venda de passagem }\end{array}$ \\
\hline Comércio & $\begin{array}{l}\text { arrumação da loja } \\
\text { pacote }\end{array}$ & $\begin{array}{l}\text { venda } \\
\text { caixa }\end{array}$ \\
\hline Fábrica & $\begin{array}{c}\text { fabricação } \\
\text { manutenção } \\
\text { ferramentaria } \\
\text { logística externa }\end{array}$ & $\begin{array}{c}\text { venda } \\
\text { assistência técnica } \\
\text { serviço atendimento consumidor }\end{array}$ \\
\hline
\end{tabular}

Figura 1 - Exemplos de agrupamento de atividades

Na área apoiadora, constituída por diversos órgãos, estão compreendidas as atividades ditas administrativas de:

- aquisição de bens e serviços, que tratam da compra de insumos e suprimentos em geral, incluindo seleção, desenvolvimento e acompanhamento de fornecedores (um departamento centralizado de compras seria uma área apoiadora; um órgão de compras específico para a produção, seria uma subárea apoiadora da área produtora);

- gestão de recursos humanos, que tratam da descrição de funções, do recrutamento, seleção, contratação, remuneração e desenvolvimento de pessoal, do cadastro de fun- cionários, dos benefícios, da folha de pagamento, das negociações trabalhistas e de outras atividades correlatas;

- gestão financeira e contábil, incluindo contabilidade, fluxo de caixa, contas a pagar, contas a receber, faturamento;

- projeto dos sistemas de informação, envolvendo os financeiros, os de recursos humanos, os de produção, os de troca eletrônica de dados (interna e externa), os de marketing e vendas, os de $\mathrm{P} \& \mathrm{D}$, os de comunicação (tipo call center), os gerenciais para tomada de decisão; $\mathrm{e}$

- outras atividades de caráter administrativo, como as jurídicas e as de relações governamentais. 


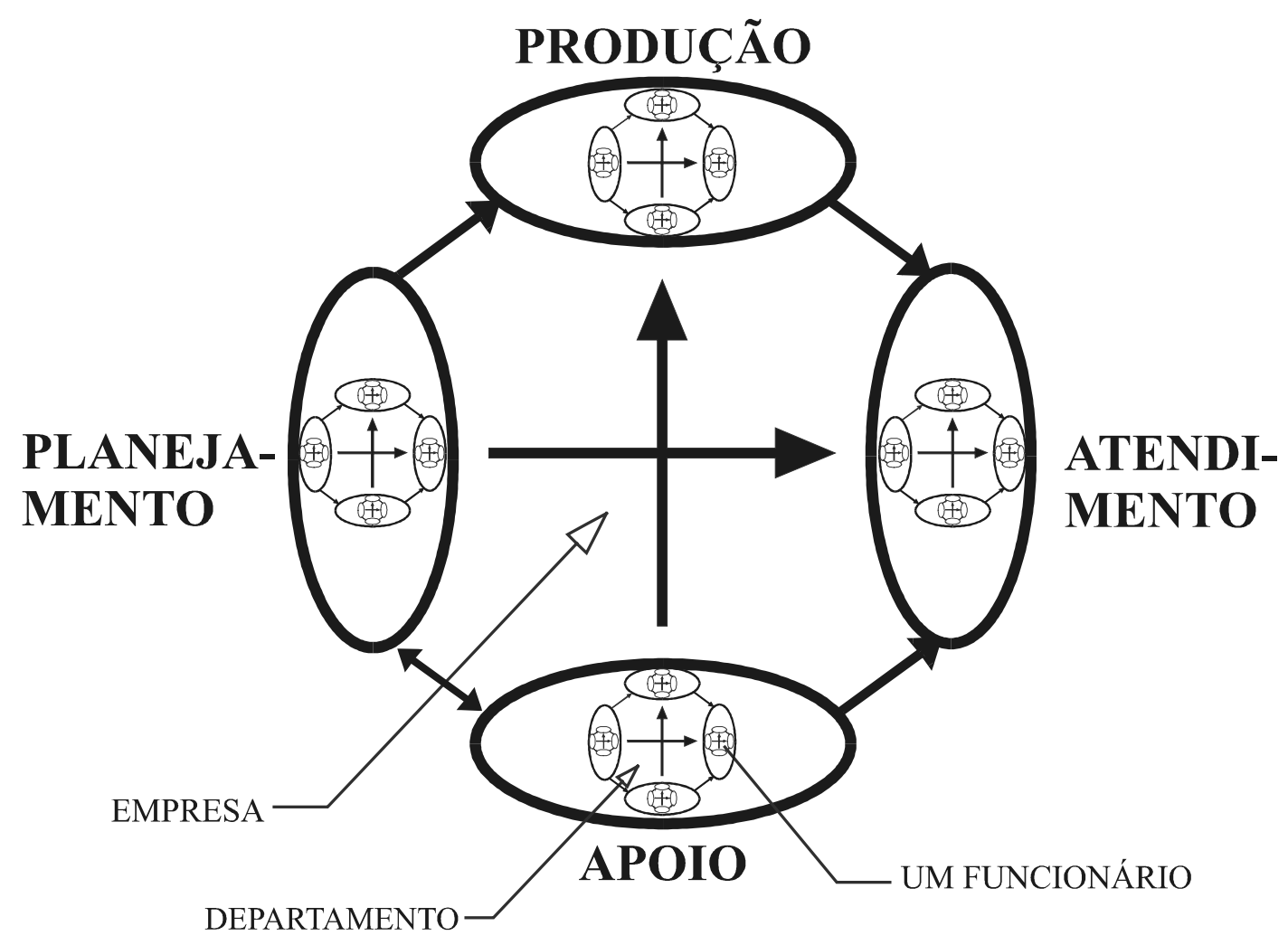

Figura 2 - Modelo das atividades da empresa

Na área produtora, constituída por diversos órgãos, estão compreendidas principalmente as atividades de:

- produção propriamente dita de bens, que transformam os insumos em produto, como a fabricação de geladeira;

- produção propriamente dita de serviços, que transformam os insumos em serviços, como a lavagem de roupa num hotel ou a restauração de um dente ou o conserto de um produto numa oficina de assistência técnica ou a instalação de produto para o cliente ou a embalagem de um produto industrial;

- planejamento e controle da produção de bens e serviços, incluindo o controle de estoques;

- gestão da qualidade;

- logística interna, que cuidam do recebimento, armazenamento e distribuição de insumos para a produção de bens ou serviços, incluindo a programação de frotas e outras atividades correlatas;
- logística externa, que cuidam do armazenamento e distribuição de produtos ou serviços aos clientes, incluindo a programação de frotas e outras atividades correlatas;

- projeto de produto ou do serviço, incluindo especificação do desempenho, construção e teste de protótipos, teste de campo; e

- manutenção e ferramentaria.

Na área atendedora, constituída por diversos órgãos, estão compreendidas as atividades que são realizadas na presença física do cliente ou à distância, como:

- atendimento pessoal, que no setor de serviços são conhecidas por atividades de frente ou de front office, como as do maître, as do concièrge, as do barbeiro;

- atendimento à distância, como comércio eletrônico, call center, correio eletrônico;

- marketing, como pesquisa de mercado para inquirir as necessidades e anseios do consu- 
midor, identificação das estratégias dos concorrentes, fixação de preço, estimativa de demanda, definição dos locais e dos meios de oferta de produtos ou serviços aos clientes, propaganda, seleção de canal de veiculação;

- vendas, incluindo proposta de venda com especificação do produto ou serviço e cotação de preço, promoção de vendas, administração da força de vendas, cadastro de clientes, telemarketing, comércio eletrônico, home page e outras atividades típicas.

As atividades têm grau de importância variável em função do tipo de empresa e do tipo de órgão, dependendo de onde se origina a vantagem competitiva. Numa empresa industrial, as atividades da produção têm maior grau de importância que as de atendimento ao cliente. Num restaurante, as atividades da cozinha e as do atendimento pessoal ao cliente têm graus de importância equivalentes. Num hotel, as atividades de atendimento pessoal têm maior grau de importância que as da lavanderia. No departamento de vendas de uma fábrica, as atividades de atendimento têm maior grau de importância que as da preparação da proposta de venda, que é atividade produtora. Na cozinha de um restaurante, a preparação de pratos, que é atividade produtora, tem maior grau de importância que o atendimento ao garçom. No salão de um restaurante, as atividades de atendimento têm maior grau de importância que as da produção do garçom, como arrumar mesa ou transportar pratos a servir.

Com alguma freqüência, aparecem conjuntos vazios, que correspondem à não existência de algum grupo atividade (área ou subárea) num órgão, como no exemplo da Figura 4, onde a Seção de Logística Interna não possui um setor de atendimento. A existência de conjuntos vazios não invalida o modelo.

\section{Validação do Modelo das Atividades da Empresa}

A visão da empresa, como ilustrada pela Figura 2, permite constatar que:
- as atividades da empresa podem ser agrupadas em quatro áreas: a planejadora, a apoiadora, a produtora e a atendedora;

- cada área é constituída por quatro subáreas: a planejadora, a apoiadora, a produtora e a atendedora;

- a área planejadora tem atuação sobre as outras três áreas, assim como as subáreas planejadoras atuam sobre as outras três subáreas;

- a área apoiadora apóia as outras três áreas, e as subáreas apoiadoras de qualquer área apóiam as outras três subáreas;

- a área produtora produz para o cliente externo, e as subáreas produtoras de qualquer área produzem para o cliente interno; e

- a área atendedora atende o cliente externo, e as subáreas atendedoras de qualquer área atendem o cliente interno.

As setas da Figura 2 indicam as relações entre as áreas, quer de informação, quer de suporte. Assim, as atividades do atendimento, para serem bem realizadas, precisam das atividades de produção, de apoio e de planejamento. As atividades da produção, para serem realizadas, precisam das atividades de apoio e de planejamento. As atividades de apoio precisam das de planejamento. As atividades de planejamento precisam das de apoio. As setas procuram indicar o fluxo primeiro de informações, não querendo sugerir que não haja fluxo de informações do atendimento para as outras áreas.

A definição das atividades do modelo, feita no item anterior, evidencia que todas as atividades da empresa, inclusive as da organização informal, são contempladas por ele, o que significa que o modelo é aplicável à empresa como um todo. A Figura 3 mostra como os diversos departamentos de uma empresa industrial podem ser agrupados nas quatro áreas e nas quatro subáreas. A área de produção, no exemplo, possui quatro departamentos distribuídos em três subáreas.

Além de o modelo ser aplicável à empresa como um todo, para sua validação integral é necessário constatar sua aplicabilidade a 
ÁREAS E SUBÁREAS DE UMA EMPRESA INDUSTRIAL TÍPICA

\begin{tabular}{l|l|l|l|l}
\hline \hline \multicolumn{1}{c|}{ Áreas de } & \multicolumn{1}{|c|}{$\begin{array}{c}\text { Subárea de } \\
\text { planejamento }\end{array}$} & Subárea de apoio & \multicolumn{1}{|c}{$\begin{array}{c}\text { Subárea de } \\
\text { produção }\end{array}$} & \multicolumn{1}{c}{$\begin{array}{c}\text { Subárea de } \\
\text { atendimento }\end{array}$} \\
\hline Planejamento & & $\begin{array}{l}\text { Pesquisa \& } \\
\text { Desenvolvimento }\end{array}$ & $\begin{array}{l}\text { Planejamento } \\
\text { Estratégico }\end{array}$ & \\
\hline Apoio & $\begin{array}{l}\text { Estratégias de } \\
\text { Sistemas }\end{array}$ & $\begin{array}{l}\text { Depto. Financeiro } \\
\text { Depto. Projeto de } \\
\text { Sistemas }\end{array}$ & $\begin{array}{l}\text { Depto. de Compras } \\
\text { Depto. de Recursos } \\
\text { Humanos }\end{array}$ & $\begin{array}{l}\text { Depto. Relações } \\
\text { Govern. }\end{array}$ \\
\hline Produção & $\begin{array}{l}\text { Depto. Projeto de } \\
\text { Produtos }\end{array}$ & $\begin{array}{l}\text { Depto. Manutenção / } \\
\text { Ferram. } \\
\text { Depto. Gestão da } \\
\text { Qualidade }\end{array}$ & $\begin{array}{l}\text { Departamentos de } \\
\text { Produção }\end{array}$ & \\
\hline Atendimento & Depto. de Marketing & $\begin{array}{l}\text { Depto. Administ. de } \\
\text { Vendas }\end{array}$ & $\begin{array}{l}\text { Depto. Logística } \\
\text { Externa }\end{array}$ & Depto. de Vendas \\
\hline
\end{tabular}

Figura 3 - Áreas e subáreas de uma empresa industrial típica

qualquer órgão e a qualquer célula da empresa. Assim será feito. Para cada subárea (planejamento, apoio, produção e atendimento), serão dados exemplos para um órgão (departamento, seção ou setor) e para uma célula de trabalho, considerando, como empresas típicas, uma empresa industrial e um restaurante e, como órgãos típicos de uma empresa qualquer, o departamento de vendas representando a área atendedora e o departamento de $\mathrm{RH}$ representando a área apoiadora.

\subsection{Aplicação do modelo a uma empresa industrial}

A Figura 4 mostra o departamento de produção de uma empresa industrial constituído por várias seções. Cada seção é constituída por vários setores, que são constituídos por subsetores. As atividades de cada um desses órgãos estão distribuídas nas quatro subáreas. Observa-se que a Seção de Fundição não possui setor específico encarregado do atendimento ao cliente interno (no caso, o Setor de Acabamento), caracterizando um conjunto vazio. $\mathrm{O}$ mesmo ocorre com o setor e o subsetor. Mas, não existe atividade de atendimento? Sim, ela sempre existe. Nesse caso, é desempenhada pelo operário, o esmerilhador, e não por um órgão. Em outros casos, será desempenhada pelo funcionário.

Deve ser ressaltado que o nível hierárquico de qualquer órgão não tem importância para o modelo. O que importa são as atividades, que sempre podem ser agrupadas nas quatro subáreas. O PCP, qualquer que seja seu nível hierárquico, apesar de estar caracterizado na Figura 4 como uma seção, no mesmo nível hierárquico da Seção de Fundição e da de Usinagem, tem atividades distribuídas pelas quatro subáreas.

A Figura 4 mostra que:

- a subárea produtora produz para um cliente interno (a Seção de Usinagem produz para a Seção de Expedição);

- a subárea atendedora atende um cliente interno (a Expedição atende os vendedores da empresa dando-lhes informações);

- a subárea apoiadora apóia a subárea produtora (a Seção de Logística Interna distribui materiais a serem transformados) e apóia a subárea atendedora (o PCP controla as atividades da expedição); e 
SUBÁREAS DE UM DEPTO. DE PRODUÇÃO INDUSTRIAL

\begin{tabular}{|c|c|c|c|c|}
\hline Órgão & $\begin{array}{c}\text { Subárea de } \\
\text { planejamento }\end{array}$ & Subárea de apoio & $\begin{array}{l}\text { Subárea de } \\
\text { produção }\end{array}$ & $\begin{array}{c}\text { Subárea de } \\
\text { atendimento }\end{array}$ \\
\hline $\begin{array}{l}\text { Depto. de } \\
\text { Produçãao }\end{array}$ & $\begin{array}{l}\text { Seção de PCP emite } \\
\text { O. F. } \\
\text { Seção PCP } \\
\text { programa logística }\end{array}$ & $\begin{array}{l}\text { Seção de Logística } \\
\text { Interna } \\
\text { Seção de PCP libera } \\
\text { produção }\end{array}$ & $\begin{array}{l}\text { Seção de Fundição } \\
\text { Seção de Usinagem }\end{array}$ & Seção de Expedição \\
\hline $\begin{array}{l}\text { Seção de } \\
\text { Fundiçãao }\end{array}$ & $\begin{array}{l}\text { Programa tipos de } \\
\text { ligas } \\
\text { Programa corridas } \\
\text { diferentes }\end{array}$ & $\begin{array}{l}\text { Setor Preparação de } \\
\text { Coquilha }\end{array}$ & $\begin{array}{l}\text { Setor de Fundição } \\
\text { em Coquilha }\end{array}$ & \\
\hline $\begin{array}{l}\text { Setor de } \\
\text { Acabamento }\end{array}$ & $\begin{array}{l}\text { Programa escala de } \\
\text { operários }\end{array}$ & $\begin{array}{l}\text { Transporta peças } \\
\text { internamente }\end{array}$ & $\begin{array}{l}\text { Subsetor de } \\
\text { Rebarbação } \\
\text { Subsetor de } \\
\text { Desempeno } \\
\text { Subsetor de } \\
\text { Limpeza de Peças }\end{array}$ & \\
\hline $\begin{array}{l}\text { Subsetor de } \\
\text { Rebarbação }\end{array}$ & $\begin{array}{l}\text { Distribui operários } \\
\text { internos }\end{array}$ & Prepara máquinas & $\begin{array}{l}\text { Executa rebarbação } \\
\text { Executa } \\
\text { esmerilhação } \\
\text { Executa lixação }\end{array}$ & \\
\hline Esmerilhador & $\begin{array}{l}\text { Decide como fazer } \\
\text { seu trabalho }\end{array}$ & $\begin{array}{l}\text { Troca e afia } \\
\text { ferramentas } \\
\text { Anota problemas no } \\
\text { relatório }\end{array}$ & Esmerilha peças & Atende o lixador \\
\hline Seção de PCP & $\begin{array}{l}\text { Planejamento da } \\
\text { produção }\end{array}$ & $\begin{array}{l}\text { Planej. processo } \\
\text { produtivo }\end{array}$ & $\begin{array}{l}\text { Progr. e controle da } \\
\text { produção }\end{array}$ & $\begin{array}{l}\text { Liberação da } \\
\text { produção }\end{array}$ \\
\hline $\begin{array}{l}\text { Seção Logística } \\
\text { Interna }\end{array}$ & $\begin{array}{l}\text { Determina tipo } \\
\text { equipamento } \\
\text { (empilhadeira ou } \\
\text { comboio) }\end{array}$ & $\begin{array}{l}\text { Troca garfos da } \\
\text { empilhadeira } \\
\text { Abastece } \\
\text { empilhadeira }\end{array}$ & Transporta peças & \\
\hline Empilhadeirista & Define rotas & $\begin{array}{l}\text { Consulta ordens de } \\
\text { transporte }\end{array}$ & Transporta peças & Atende operários \\
\hline Seç. Expedição & $\begin{array}{l}\text { Setor Preparação de } \\
\text { Romaneio }\end{array}$ & & $\begin{array}{l}\text { Setor de Separação } \\
\text { de Produtos }\end{array}$ & $\begin{array}{l}\text { Setor de } \\
\text { Atendimento a } \\
\text { Vendas }\end{array}$ \\
\hline Separador & $\begin{array}{l}\text { Planeja como } \\
\text { trabalhar }\end{array}$ & Consulta romaneio & Separa produtos & $\begin{array}{l}\text { Atende } \\
\text { transportador }\end{array}$ \\
\hline
\end{tabular}

Figura 4 - Subáreas de um departamento de produção industrial 
- a subárea planejadora toma decisões para a subárea produtora (o PCP emite ordens de fabricação - O.F.), toma decisões para a subárea atendedora (o PCP determina critérios de prioridade para a expedição de produtos) e toma decisões para a subárea apoiadora (o PCP programa as atividades da logística interna).

A Figura 4 se presta também para mostrar que o modelo é aplicável a tantos níveis hierárquicos quantos os existentes na empresa. Note-se sua aplicação ao nível mais baixo, a uma célula de trabalho, mesmo aquela constituída por apenas uma pessoa. No exemplo, o esmerilhador:

- enquanto produtor, executa uma operação numa peça (esmerilha);

- enquanto atendedor, atende seu cliente, que é o operário responsável pela suboperação seguinte na mesma peça (lixador);

- enquanto apoiador, apóia a si mesmo para produzir, trocando ferramenta ou lubrificando a máquina, e apóia a si mesmo para atender, anotando num relatório eventuais problemas ocorridos nas peças; e

- enquanto planejador, planeja suas atividades produtora, atendedora e apoiadora, ou seja, como realizará sua produção, quando lubrificará sua máquina e como fará o relatório.

A existência de atividades em quatro subáreas, evidenciada nesse exemplo, reforça a idéia, antítese do Taylorismo, do enriquecimento de cargos, tão necessário ao incremento da competitividade da empresa moderna.

\subsection{Aplicação do modelo a uma empresa de serviços}

Como se aplicaria o modelo a uma empresa de serviços? Tome-se, a título de exemplo, um restaurante e considerem-se os três níveis de interesse, quais sejam, empresa como um todo, sua área produtora e uma célula de trabalho, como mostrado pela Figura 5.

$\mathrm{O}$ restaurante, entendido como uma empresa, tem, como área produtora, a cozinha, que produz pratos para o cliente externo; tem, como área atendedora, o salão; tem, como área apoiadora à produção, o departamento de compras de mantimentos e, como apoiadora ao atendimento, o departamento de RH, que contrata garçons; e tem área planejadora, que define o cardápio diário a ser preparado pela área produtora (cozinha), que faz a escala dos garçons da área atendedora e que dá diretrizes ao departamento de compras (área apoiadora).

Tome-se, agora, a cozinha, que é a área produtora do restaurante:

- uma de suas subáreas produtoras arranja o prato de maneira elegante e criativa;

- a subárea atendedora da cozinha atende seu cliente interno, que é o garçom;

- as subáreas apoiadoras das subáreas produtoras preparam alimentos básicos comuns a muitos pratos, como arroz e batata, e a subárea apoiadora ao atendimento anota o número da mesa a que se destina o prato; e

- a subárea planejadora determina, para a subárea produtora, as atividades de cada um dos cozinheiros; determina, para a subárea atendedora, como atender garçons; programa, para a subárea apoiadora à produção, a quantidade de alimentos básicos a ser produzida e determina, para a subárea apoiadora ao atendimento, como anotar o número da mesa.

Tome-se, agora, um ajudante de cozinha, que é uma célula de trabalho da subárea produtora. Suas atividades, que têm como cliente o cozinheiro, também podem ser agregadas nas quatro subsubáreas. Descascar batatas é uma atividade produtora; atender o cozinheiro é uma atividade atendedora; afiar facas é uma atividade apoiadora à produção e obedecer às instruções do cozinheiro é uma atividade apoiadora ao atendimento; e autoprogramar a seqüência das suas operações é uma atividade planejadora da sua célula.

\subsection{Aplicação do modelo às áreas atendedora, apoiadora e planejadora}

Os exemplos anteriores restringiram-se à área produtora (empresa industrial e restaurante). Como ficariam as áreas atendedora, apoiadora e 
ÁREAS E SUBÁREAS DE UM RESTAURANTE

\begin{tabular}{|c|c|c|c|c|}
\hline Órgão & $\begin{array}{c}\text { Área ou Subárea de } \\
\text { planej. }\end{array}$ & $\begin{array}{c}\text { Área ou Subárea de } \\
\text { apoio }\end{array}$ & $\begin{array}{l}\text { Área ou Subárea de } \\
\text { produção }\end{array}$ & $\begin{array}{c}\text { Área ou Subárea de } \\
\text { atendim. }\end{array}$ \\
\hline Empresa & $\begin{array}{l}\text { Planeja cardápio } \\
\text { Define escala de } \\
\text { garçons } \\
\text { Define diretrizes } \\
\text { para compras }\end{array}$ & $\begin{array}{l}\text { Depto. de Compras } \\
\text { Depto. de RH }\end{array}$ & Cozinha & Salão \\
\hline Cozinha & $\begin{array}{l}\text { Determina tarefas } \\
\text { cozinheiros } \\
\text { Define como atender } \\
\text { garçons } \\
\text { Programa quantidade } \\
\text { alimentos }\end{array}$ & $\begin{array}{l}\text { Seção de Alimentos } \\
\text { Básicos } \\
\text { Anotação do } n .^{\circ} \text { da } \\
\text { mesa }\end{array}$ & $\begin{array}{l}\text { Seção de Assados } \\
\text { Seção de Arranjo de } \\
\text { Pratos }\end{array}$ & $\begin{array}{l}\text { Atendimento a } \\
\text { garçons }\end{array}$ \\
\hline $\begin{array}{l}\text { Ajudante de } \\
\text { cozinha }\end{array}$ & $\begin{array}{l}\text { Programa suas } \\
\text { operações }\end{array}$ & $\begin{array}{l}\text { Afia facas } \\
\text { Obedece instruções } \\
\text { cozinheiro }\end{array}$ & Descasca batatas & Atende cozinheiro \\
\hline
\end{tabular}

Figura 5 - Áreas e subáreas de um restaurante

planejadora de uma empresa qualquer, quando focadas pela óptica do modelo das atividades da empresa? A Figura 6 ilustra o departamento de vendas representando a área atendedora e o departamento de $\mathrm{RH}$ representando a área apoiadora.

A subárea produtora do departamento de vendas produz a proposta de venda, que será encaminhada a um vendedor. A subárea atendedora é representada pela equipe de vendedores. A subárea apoiadora à subárea produtora de vendas é representada pelo sistema de cotação de preços, e a subárea apoiadora à subárea atendedora, pelos sistemas de cadastro de clientes e de informações sobre os concorrentes, principalmente sobre produtos e modos de negociação. A subárea planejadora planeja as atividades operacionais do departamento.

Tome-se, agora, um vendedor como uma célula de trabalho da área atendedora. $\mathrm{O}$ vendedor, no seu papel produtor, prepara (produz) a negociação com o cliente externo comparando a proposta de venda com as condições dos concorrentes, que é uma atividade interna, de retaguarda. No seu papel atendedor, visita o cliente externo. No seu papel apoiador à produção de seu serviço, consulta a proposta de venda e as informações sobre os concorrentes. No papel apoiador ao atendimento, obtém diversas informações sobre o cliente que irá visitar, como, por exemplo, se é um negociador duro ou flexível. No papel planejador, programa diariamente suas atividades.

Uma das subáreas produtoras do departamento de RH cuida (produz) do recrutamento, da seleção e da contratação de um funcionário para outro órgão da empresa, que é seu cliente interno. Um departamento de RH usualmente não dispõe de uma subárea atendedora, pois o atendimento ao cliente interno é feito pelos funcionários. A subárea apoiadora à subárea produtora cuida do cadastro de currículo de candidatos e a subárea apoiadora á subárea atendedora elabora o perfil do funcionário a ser contratado. A subárea planejadora planeja as atividades operacionais do departamento. 
SUBÁREAS DE UM DEPARTAMENTO DE VENDAS E DE RH

\begin{tabular}{|c|c|c|c|c|}
\hline $\begin{array}{l}\text { Depto. } \\
\text { Vendas }\end{array}$ & $\begin{array}{l}\text { Seção de } \\
\text { Planejamento }\end{array}$ & $\begin{array}{l}\text { Sistema de cotação } \\
\text { de preços } \\
\text { Cadastro de clientes }\end{array}$ & $\begin{array}{l}\text { Seção de proposta de } \\
\text { venda }\end{array}$ & $\begin{array}{l}\text { Equipe de } \\
\text { vendedores }\end{array}$ \\
\hline Vendedor & $\begin{array}{l}\text { Programa suas } \\
\text { tarefas }\end{array}$ & $\begin{array}{l}\text { Consulta proposta de } \\
\text { venda } \\
\text { Obtém informação } \\
\text { sobre cliente }\end{array}$ & Prepara negociação & Visita cliente externo \\
\hline Depto. RH & $\begin{array}{l}\text { Planeja atividades } \\
\text { operacionais }\end{array}$ & $\begin{array}{l}\text { Cadastro de } \\
\text { currículos } \\
\text { Perfil do funcionário }\end{array}$ & $\begin{array}{l}\text { Seção Recrutamento } \\
\text { e Seleção }\end{array}$ & \\
\hline Recrutador & $\begin{array}{l}\text { Planeja suas } \\
\text { atividades }\end{array}$ & $\begin{array}{l}\text { Consulta preços de } \\
\text { jornais } \\
\text { Consulta perfil } \\
\text { funcionário }\end{array}$ & Redige anúncio & $\begin{array}{l}\text { Atende selecionador } \\
\text { de pessoal }\end{array}$ \\
\hline
\end{tabular}

Figura 6 - Subáreas de um departamento de vendas e de RH

Tome-se, agora, um recrutador de pessoal como uma célula de trabalho. No seu papel produtor, redige (produz) texto a ser publicado em jornais, especificando o perfil do funcionário a ser contratado. No seu papel atendedor, atende ao selecionador de pessoal, que é seu cliente interno. No seu papel apoiador ao atendimento, consulta o perfil do funcionário e discute as várias facetas do recrutamento com o selecionador de pessoal. No seu papel apoiador à produção, consulta os preços cobrados por vários jornais para a publicação do anúncio. No seu papel planejador, programa diariamente suas atividades.

A aplicação do modelo à área planejadora é análoga à feita para os departamentos de vendas e de RH, tornando desnecessária sua explicação.

\subsection{Conclusão}

Deve-se enfatizar que esses exemplos serviram para mostrar que o modelo é aplicável:

1. à empresa industrial e à de serviços;

2. à empresa como um todo;

3. às áreas e subáreas produtora, atendedora, apoiadora e planejadora de qualquer empresa;
4. aos órgãos de qualquer nível hierárquico; e

5. à célula de trabalho, até a representada por apenas uma pessoa.

Por inferência, é possível concluir que o modelo atende às três classes de serviços propostas por SILVESTRO (1999, p. 401): serviços profissionais, lojas ou oficinas de serviços e serviços de massa.

\section{Comparação com Outros Modelos}

característica mais marcante do modelo das Aatividades é ser aplicável a tantos níveis hierárquicos quantos os existentes na empresa, inclusive a cada célula da empresa, característica que outros modelos não possuem.

Apesar de o modelo não possuir características sistêmicas, é fundamental enfocar a empresa sistemicamente, na concepção do artigo publicado em 1955 por VON BERTALANFFY (apud, 1973). Caso contrário, o modelo não se prestará para a definição de estratégias competitivas, que é um de seus objetivos declarados. Para tanto, devem ser considerados: 
- os conceitos cibernéticos de entrada, processamento, saída, ambiente e retroação; e

- o entendimento da empresa como um sistema aberto, muito bem caracterizado por KATZ \& KAHN (1970, p. 35) e por Gareth MORGAN (1996, p. 49), entendimento que, por considerar as interações da empresa com o ambiente, é fundamental para os propósitos da Teoria da Competitividade.

É de interesse comparar a contribuição do presente modelo com a de outros três modelos sistêmicos bastante conhecidos: o Sociotécnico de Tavistock, o de Katz e Kahn e o de Kast e Rosenzweig.

A grande contribuição do consagrado Modelo Sociotécnico de Tavistock, proposto em 1963, foi considerar a empresa como um sistema aberto constituído pelo subsistema técnico e pelo social inter-relacionados, amalgamando os conhecimentos da Administração Científica com os da Teoria das Relações Humanas.

A grande contribuição do Modelo de KATZ \& KAHN (1970) foi aplicar, às organizações empresariais, de forma bastante coerente, os conceitos de sistema aberto propostos, com base em pesquisas biológicas, por Burton em 1939 e por von Bertalanffy em 1940 (apud VON BERTALANFFY, 1973) e incorporados no clássico Teoria Geral dos Sistemas de von Bertalanffy.

A grande contribuição do modelo de Kast e Rosenzweig, proposto em 1973 (apud MORGAN, p. 52), foi identificar cinco subsistemas organizacionais (estratégico, técnico, estrutural, humano-cultural e gerencial), envolvidos por um supra-sistema ambiental.

A grande contribuição do modelo das atividades da empresa é identificar que os quatro grupos de atividades (planejamento, apoio, produção e atendimento) ocorrem em toda a empresa, ou seja, identificar que as atividades, quer da empresa como um todo, quer de qualquer unidade organizacional, quer de cada célula de trabalho (representada até por apenas um funcionário), podem ser agregadas nesses quatro grupos.
Os três modelos anteriores enfatizam as relações da empresa com o ambiente e o conceito cibernético de fluxo (entrada, processamento, saída e retroação), considerando a empresa quase como uma caixa preta, não se preocupando com o fluxo interno da empresa. Eles se complementam no sentido de seus conceitos poderem ser usados simultaneamente na análise da empresa, ou seja, pode-se aplicar o conceito de subsistemas técnico e social do Modelo de Tavistock aos cinco subsistemas do modelo de Kast e Rosenzweig e aliar aos dois modelos a contribuição de Katz e Kahn sobre sistemas abertos.

O presente modelo, como mostrado na Figura 2 , enfatiza as atividades realizadas e os fluxos internos, não de materiais, mas de informação e de suporte (quer na empresa como um todo, quer em cada departamento, quer em cada célula de trabalho). Por forçar o estrategista a mergulhar na empresa, ele permite, como nenhum outro, a análise das atividades internas da empresa e deve ser utilizado em conjunto com os conceitos dos outros modelos.

Enfim, o presente modelo complementa os anteriores. Por enfatizar as atividades e os fluxos internos de informação e de suporte, presta-se muito bem, pelas razões expostas no item 9, para a análise e proposição de estratégias competitivas, pois facilita a atuação da empresa sobre a organização das atividades e dos fluxos.

\section{Revisão de Quatro Conceitos Sobre Serviços}

A lguns conceitos precisam ser colocados A preliminarmente.

GIANESI \& CORRÊA (1996, p. 32) afirmam:

"Com frequiência, a discussão sobre o que são serviços e o que é manufatura cai no equívoco de tentar classificar as empresas, nesta ou naquela categoria... A classificação de uma empresa em particular é uma tarefa difícil já que, quase todas as vezes que se compra um produto, este vem acompanhado de um serviço facilitador, ao passo que 
quando um serviço é comprado, quase sempre vem acompanhado de um produto facilitador...

...Contudo estabelecer diferenças entre sistemas de operações (e não entre empresas)... é útil e oportuno.

As principais características especiais das operações de serviço são:

- a intangibilidade dos serviços;

- a necessidade da presença do cliente ou um bem de sua propriedade; e

- o fato de que geralmente os serviços são produzidos e consumidos simultaneamente."

Para McCARTHY \& PERREAULT (1997, p. 150):

"A maioria dos produtos é uma combinação de elementos tangíveis e intangíveis... Um hambúrguer McDonald's é tangível, mas o serviço rápido não é.

Geralmente, os bens são produzidos em uma fábrica e, depois, vendidos... Em contraste, os serviços, freqüientemente, são primeiramente vendidos e depois produzidos. Também são produzidos e consumidos ao mesmo tempo...

Os serviços são perecíveis e não podem ser estocados..."

Para a introdução de mudanças no bojo da empresa que aumentem seu grau de competitividade, propósito do presente modelo, não há diferença entre a oferta de produtos e a prestação de serviços. O modelo, focando as atividades da empresa, evidencia que sempre há atendimento, que é intangível, e produção, que pode ser tangível ou intangível. Uma relojoaria, ao trocar a bateria de um relógio, presta um serviço tangível, composto por um atendimento (recebimento do relógio) e uma produção tangível (troca da bateria) feita sem a presença do cliente, mas com a presença de um bem seu. Numa sala de aula, o professor presta um serviço intangível, composto também por um atendimento (responder uma dúvida do aluno) e uma produção intangível (ministrar a aula), exigindo a presença do aluno (mesmo que à distância). Uma das atividades apoiadoras do professor é a preparação do material didático, que precisa ser produzido antecipadamente.

A característica fundamental do atendimento é a cortesia; a da produção, a competência técnica. Uma atendente de um laboratório de análises clínicas precisa ser cortês com o paciente, no momento em que o modelo classifica como atendimento, e competente ao preencher os dados do paciente no cadastro, no momento em que o modelo classifica como produção, mesmo que realizada na presença do paciente.

Colocados esses pontos, é conveniente esclarecer com precisão quatro conceitos expostos por consagrados autores sobre serviços:

1. intangibilidade dos serviços;

2. necessidade da presença do cliente;

3. simultaneidade entre produção e consumo; e

4. impossibilidade de estocar serviços.

Existe o conceito bastante disseminado sobre a intangibilidade dos serviços: são experiências e sensações vivenciadas pelo consumidor. Isso só é inteiramente verdade para as atividades que exigem a presença do cliente, que são as atividades de atendimento e as de produção da parte intangível do serviço. Não se pode afirmar que a troca da bateria do relógio seja intangível, que as refeições produzidas por um restaurante sejam intangíveis, embora seu sabor o seja.

A necessidade da presença do cliente para a realização do serviço também é afirmação válida somente para as atividades de atendimento e para as de produção da parte intangível do serviço. O restaurante prepara previamente pratos antes da chegada do cliente, o que caracteriza que a produção da parte tangível do serviço pode ser feita sem a presença do cliente, e freqüentemente o é. A produção da parte intangível do serviço, como ministrar aula ou preencher o cadastro do cliente, precisa da presença do cliente.

O terceiro conceito - serviços são produzidos e consumidos simultaneamente - nem sempre é verdadeiro, apesar de freqüentemente ocorrer a 
produção do serviço (tangível ou intangível) durante o atendimento, como no caso do dentista, do cabeleireiro, do caixa bancário. Mas, não é valido para o protético, para a oficina de conserto e para o restaurante que prepara previamente os pratos.

O quarto conceito - os serviços não podem ser estocados - é decorrência do terceiro. Partindo-se da premissa, que é incompleta por não ser geral, de que a produção e o consumo de serviços são simultâneos, conclui-se que os serviços não podem ser estocados porque não podem ser produzidos antes da chegada do cliente. Não podendo ser estocados, a empresa de serviços sofre diretamente os impactos das variações do ambiente externo (imprevisibilidade da demanda, mudança no prazo ou no produto solicitada pelo cliente etc.) e, portanto tem dificuldade para utilizar eficientemente a capacidade produtiva de prestação de serviço, pois aquela capacidade disponível, que não for utilizada devido à inexistência de demanda em alguns momentos, é perdida para sempre (GIANESI \& CORRÊA, 1997, p. 461).

Ora, essas considerações são válidas apenas para as atividades de atendimento e para as de produção da parte intangível dos serviços. As de produção tangível têm a mesma natureza das atividades de produção fabril e podem, portanto, ser estocadas: o hotel estoca roupa de cama lavada, o restaurante estoca arroz pronto para servir, a boutique estoca embalagem semi-pronta.

A imprecisão desses quatro conceitos decorre de dois pensamentos imprecisos: quando se pensa em serviço, pensa-se quase exclusivamente em atendimento na presença do cliente e, quando se pensa em produto associado a serviços, pensa-se em produto tangível. O presente modelo serve para precisar os conceitos porque diferencia as atividades de atendimento das produtoras e evidencia que, além do atendimento, há produtos intangíveis. Enfim, para que não restem dúvidas, deve-se conceituar os serviços como sendo compostos por atividades atendedoras e produtoras, estas resultando em produtos tangíveis ou intangíveis.
$\mathrm{O}$ atendimento sempre é intangível. A produção do serviço pode ser tangível ou intangível.

Somente as atividades de atendimento e de produção intangível exigem a presença do cliente.

A parte tangível do serviço pode ser produzida antes do consumo e estocada.

\section{Comparação com o Modelo de Porter}

$\mathrm{O}$ modelo mais difundido para análise da competitividade empresarial é o do protomestre Michael Porter, denominado Cadeia de Valores. Já que o presente modelo serve aos propósitos da Teoria da Competitividade, é conveniente comparar esses dois modelos.

Para Michael PORTER (1989), a empresa deve ser modelada segundo a cadeia de valores, agrupando as atividades realizadas na empresa em:

- atividades primárias: logística interna, operações, logística externa, marketing e vendas, e serviços; e

- atividades de apoio: infra-estrutura da empresa, gerência de recursos humanos, desenvolvimento de tecnologia e aquisição.

O modelo de Porter separa as atividades empresariais em primárias e de apoio. O presente modelo separa-as em produtoras, atendedoras, apoiadoras e planejadoras, possibilitando uma análise mais acurada das atividades que criam valor para o consumidor.

O modelo de Porter foca a empresa como um todo. Os quatro tipos de atividades do presente modelo valem para a empresa como um todo, para qualquer órgão e para cada célula de trabalho, evidenciando, o que é muito importante, que todos os órgãos e todos os funcionários desempenham atividades produtoras, atendedoras, apoiadoras e planejadoras.

O modelo de Porter não enfatiza as atividades atendedoras. E, hoje, o atendimento é tão importante para o consumidor quanto o produto ou serviço. A indústria gastronômica, percebendo 
isto, dá duas classificações distintas aos restaurantes: simboliza por estrelas exclusivamente a qualidade da cozinha e por garfos a categoria das instalações e do conforto. Ou seja, distingue a área produtora da área de atendimento, como no presente modelo.

O presente modelo, por separar as atividades de interesse do consumidor em produtoras e atendedoras, facilita sobremaneira a identificação dos campos e das armas da competição. Mas, este assunto fica para um próximo artigo. (Para os interessados, recomendam-se os capítulos 3 e 4 do Modelo para aumentar a competitividade industrial.)

Por essas razões, o presente modelo revela-se adequado para definir as estratégias competitivas, pois possibilita analisar as entranhas da empresa com bastante acuidade. A aplicação dos preciosos ensinamentos de Porter, com a ajuda do presente modelo, evidencia com nitidez as mudanças necessárias no bojo da empresa para torná-la mais competitiva.

\section{Vantagens do Modelo das Atividades da Empresa}

$\mathrm{P}$ ara finalizar, é conveniente resumir as vantagens do presente modelo, além das já mencionadas no item anterior. Assim, sem hierarquização dos tópicos seguintes, o modelo:

1. possibilita às empresas do setor de serviços utilizar, nas atividades de produção, as técnicas administrativas industriais, e às empresas industriais utilizar, nas atividades de atendimento, as técnicas administrativas desenvolvidas para e pelas empresas de serviços;

2. unifica o pensamento dos autores que tratam preferencialmente das empresas de serviços com o pensamento daqueles que tratam preferencialmente das empresas industriais, fazendo com que cada um desses tipos de empresa se beneficie dos avanços administrativos obtidos pelo outro tipo;

3. é aplicável à empresa industrial e à de serviços, à empresa como um todo, e a qualquer nível hierárquico, inclusive à célula de trabalho representada por apenas uma pessoa;

4. possibilita preparar e treinar melhor os funcionários, pois enfatiza os quatro grupos de atividades que precisa executar;

5. auxilia a aplicação dos ensinamentos daqueles autores sobre estratégia empresarial que não fazem distinção entre empresa de serviços e empresa industrial, facilitando a identificação das especificidades de um tipo e de outro;

6. evidencia que qualquer unidade organizacional e qualquer funcionário devem executar as atividades das áreas produtora, atendedora, apoiadora e planejadora;

7. identifica nitidamente as atividades-fim (produção e atendimento) das atividadesmeio (apoio e planejamento), evidenciando que o cliente tem interesse apenas nas atividades-fim e que é nelas que a empresa pode competir, o que facilita a escolha do campo da competição e, por decorrência, das armas da competição;

8. eleva as atividades de atendimento ao mesmo nível de importância das de produção;

9. enfatiza as atividades internas e os fluxos de informação e de suporte internos da empresa, facilitando a definição das estratégias competitivas, pois é sobre as atividades e sobre os fluxos que a empresa deve atuar para aumentar seu grau de competitividade;

10. complementa outros modelos que consideram a empresa quase uma caixa preta;

11. permite uma conceituação mais precisa sobre as atividades das empresas de serviços, evidenciando que o atendimento é intangível, que há produto intangível, que somente as atividades de atendimento e de produção intangíveis exigem a presença do cliente e que a parte tangível do serviço pode ser produzida antes do consumo e estocada (item 7); e

12. obriga, como nenhum outro modelo, o estrategista a mergulhar dentro da empresa $\mathrm{e}$ não apenas a voar sobre ela. 
A última vantagem do modelo a ser mencionada é a de auxiliar o processo de entendimento da empresa. Entendê-la é fundamental para gerila, para aperfeiçoá-la e para torná-la mais competitiva. E para torná-la mais competitiva, é necessário mudá-la quase diariamente. Por que mudá-la quase diariamente? Porque o mercado muda também muito rapidamente: novos produtos concorrentes, novas empresas concorrentes, novos consumidores, novas necessidades e novos anseios dos consumidores, novas tecnologias. Para esse processo de mudança, o modelo pode ser muito útil, pois mostra a empresa por um ângulo novo. $\mathrm{E}$, sobre isto, ZACCARELLI (2001) é incisivo: "Como as organizações são muito complexas, não é possível entendê-las sem o uso de múltiplas imagens."

Interessante observar que a adoção do modelo altera a descrição de funções, que passariam a ser descritas de acordo com as atividades realizadas nas quatro áreas.

\section{Conclusão}

Com este modelo, o autor espera ter contribuído para o estudo das organizações. Procurou-se, neste artigo, mostrar sua validade e suas vantagens e lançá-lo à discussão pública.

Necessário, entretanto, validá-lo nas aplicações práticas, o que caberá também a outros pesquisadores. $\mathrm{O}$ autor, desde já, agradece as críticas e sugestões, tanto para confirmar ou rejeitar sua validade como para aperfeiçoá-lo.

\section{Agradecimento}

Várias pessoas analisaram e deram sugestões sobre o artigo. $\mathrm{O}$ autor agradece a todos, em especial a colaboração dos professores Sérgio Baptista Zaccarelli, Oswaldo Fadigas Fontes Torres, Pedro Luiz de Oliveira Costa Neto, René Henrique Licht, Denis Donaire, José Luiz Contador, Carlos Alberto Contador e Manuel Meireles.

\section{Referências Bibliográficas}

CONTADOR, J.C.: Modelo para aumentar a competitividade industrial. São Paulo: Edgard Blücher, 1996.

(coord.): Gestão de operações. São Paulo: Edgard Blücher, 1997.

GIANESI, I. \& CORRÊAA, H.: "Serviços". In: CONTADOR, J.C. (coord.) Gestão de operações. São Paulo: Edgard Blücher, 1997. : Administração estratégica de serviços. São Paulo: Atlas, 1996.

KATZ, D. \& KHAN, R.: Psicologia social das organizações. São Paulo: Atlas, 1970.

McCARTHY, J. \& PERREAULT, W.: Marketing essencial. São Paulo: Atlas, 1997.

MORGAN, G.: Imagens da organização. São Paulo: Atlas, 1996.

PORTER, M.: Vantagem competitiva. Rio de Janeiro: Campus, 1989.
SILVESTRO, R.: "Positioning services along the volume-variety diagonal: the contingencies of service design, control and improvement". International Journal of Operations \& Production Management, v.19, n.4, p.399-420, 1999.

SLACK, N. et al.: Administração da produção. São Paulo: Atlas, 1997.

VON BERTALANFFY, L.: Teoria geral dos sistemas. Petrópolis: Vozes, 1973.

: "General System Theory. Main Currents in Modern Thought”, v.11, n.4, p.75-83, março 1955.

ZACCARELLI, S.B.: Administração estratégica da produção. São Paulo: Atlas, 1990.

"Entendendo como entender a organização". 2001. (Artigo a ser publicado). 


\title{
GENERAL MODEL OF COMPANY ACTIVITIES
}

\begin{abstract}
The model shows that the activities of any type of company, including service companies, can be divided into four groups (production, service, support, planning) and that such organization is applicable to the company as a whole, to any part of it (division, department) and even to single employees. Since the model, as no other, covers nearly all sections of the company, it complements other ones (Tavistock, Katz \& Kahn, Kast \& Rosenzweig). The comparison with Porter's Chain of Values and the advantages shown in the text, allow the conclusion that this model is perfectly adequate to the proposed changes in the company and to the improvement of its competitiveness.
\end{abstract}

Key words: organizational model, company activities, strategy, industrial and service company. 